\title{
Role of autophagy in temozolomide-induced cytotoxicity for malignant glioma cells
}

\author{
T Kanzawa ${ }^{1,2}$, IM Germano ${ }^{2}$, T Komata ${ }^{2}$, H Ito ${ }^{1,2}$, Y Kondo $^{1,2}$ and \\ S Kondo*,1,2 \\ 1 Department of Neurosurgery, The University of Texas MD Anderson Cancer \\ Center, Houston, TX, USA; \\ 2 Department of Neurosurgery, Mount Sinai School of Medicine, New York, NY, \\ USA \\ * Corresponding author: S Kondo, Department of Neurosurgery, The University \\ of Texas MD Anderson Cancer Center, 1515 Holcombe Blvd., Unit 64, \\ Houston, TX 77030, USA. Tel: 713-792-3526; fax: 713-794-5514; \\ E-mail: seikondo@mdanderson.org
}

Received 12.6.03; revised 15.10.03; accepted 20.10.03; published online 9.1.04 Edited by Dr. CJ Thiele

\begin{abstract}
Autophagy is originally named as a process of protein recycling. It begins with sequestering cytoplasmic organelles in a membrane vacuole called autophagosome. Autophagosomes then fuse with lysosomes, where the materials inside are degraded and recycled. To date, however, little is known about the role of autophagy in cancer therapy. In this study, we present that temozolomide (TMZ), a new alkylating agent, inhibited the viability of malignant glioma cells in a dose-dependent manner and induced G2/M arrest. At a clinically achievable dose $(100 \mu \mathrm{M})$, TMZ induced autophagy, but not apoptosis in malignant glioma cells. After the treatment with TMZ, microtubule-associated protein lightchain 3 (LC3), a mammalian homologue of Apg8p/Aut7p essential for amino-acid starvation-induced autophagy in yeast, was recruited on autophagosome membranes. When autophagy was prevented at an early stage by 3-methyladenine, a phosphatidylinositol 3-phosphate kinase inhibitor, not only the characteristic pattern of LC3 localization, but also the antitumor effect of TMZ was suppressed. On the other hand, bafilomycin $\mathrm{A1}$, a specific inhibitor of vacuolar type $\mathrm{H}^{+}$. ATPase, that prevents autophagy at a late stage by inhibiting fusion between autophagosomes and lysosomes, sensitized tumor cells to TMZ by inducing apoptosis through activation of caspase-3 with mitochondrial and lysosomal membrane permeabilization, while LC3 localization pattern stayed the same. These results indicate that TMZ induces autophagy in malignant glioma cells. Application of an autophagy inhibitor that works after the association of LC3 with autophagosome membrane, such as bafilomycin $A 1$, is expected to enhance the cytotoxicity of TMZ for malignant gliomas.

Cell Death and Differentiation (2004) 11, 448-457. doi:10.1038/ sj.cdd. 4401359

Published online 9 January 2004
\end{abstract}

Keywords: temozolomide; malignant glioma; autophagy; apoptosis; LC3
Abbreviations: TMZ, temozolomide; LC3, microtubule-associated protein light-chain 3; 3-MA, 3-methyladenine; GBM, glioblastoma multiforme; AA, anaplastic astrocytoma; AVO, acidic vesicular organelle; PI3K, phosphatidylinositol-3 kinase; GFP, green fluorescent protein; DMSO, dimethylsulfoxide; $\mathrm{Br}$ dUTP, bromolated deoxyuridine triphosphate nucleotides; FITC, fluorescent isothiocyanate

\section{Introduction}

Malignant gliomas account for approximately $50 \%$ of all central nervous system tumors. ${ }^{1,2}$ Malignant gliomas are very invasive and hardly resected en block. Even if total surgical resection of these tumors is performed, the tumors generally recur within a year. With aggressive treatment using radical surgery, radiation, and chemotherapy, the median survival time of the most malignant type, glioblastoma multiforme (GBM), is approximately a year from diagnosis. ${ }^{1,2}$ Therefore, novel strategies are essential to improve the prognosis.

A new alkylating agent, temozolomide (TMZ) has recently been introduced into clinical trials for treatment of primary or recurrent high-grade gliomas, including anaplastic astrocytoma $(A A)$ and GBM. ${ }^{3,4} \mathrm{TMZ}$ has several advantages over other existing alkylating agents because of its unique characteristics. ${ }^{5-8}$ Because TMZ is a small lipophilic molecule with a molecular weight of $194 \mathrm{Da}$, it can be administered orally and it crosses the blood-brain barrier effectively. The levels of TMZ in the brain or cerebrospinal fluid are about $30-40 \%$ of the plasma concentration. Moreover, TMZ is less toxic to the hematopoietic progenitor cells than conventional chemotherapeutic agents. It is because TMZ does not result in chemical cross-linking of the DNA strands, while other alkylating agents do crosslink the DNA. These unique pharmacological features make $\mathrm{TMZ}$ a promising agent for treating malignant gliomas.

The cytotoxicity of $T M Z$ is thought to be mainly due to the formation of $O^{6}$-methylguanine in DNA, which mispairs with thymine during the next cycle of DNA replication. ${ }^{9,10}$ Subsequent futile cell cycles of DNA mismatch repair result in cell death in hematopoietic cancer cells. ${ }^{11}$ Recent investigation shows that malignant glioma cells respond to $\mathrm{TMZ}$ by undergoing G2/M arrest and very few of glioma cells treated with TMZ underwent apoptosis. ${ }^{12}$ However, the cell death pathways in malignant glioma cells induced by $T M Z$ treatment remain poorly documented. In this study, we investigated how $\mathrm{TMZ}$ exerts antitumor activity for malignant glioma cells. We here demonstrate novel features for the action of TMZ in malignant glioma cells.

\section{Results}

Effect of TMZ on cell viability of malignant glioma cell lines

To examine the antitumor effect of $\mathrm{TMZ}$ on malignant glioma cells, we treated six malignant glioma cell lines (U373-MG, 
T98G, U251-MG, GB-1, U87-MG, and A172) with 5-1000 $\mu \mathrm{M}$ of $T M Z$ for $72 \mathrm{~h}$ and the cell viability was determined. As shown in Figure 1, TMZ inhibited the cell viability of all tumor cells in a dose-dependent manner. The $\mathrm{IC}_{50}$ (concentration resulting in cell viability of $50 \%$ of control) of TMZ for five malignant glioma cells (U373-MG, U251-MG, GB-1, U87-MG, and $\mathrm{A}-172$ ) was less than $200 \mu \mathrm{M}$. On the other hand, T98G cells turned out to be the most resistant to $\mathrm{TMZ}$ $\left(\mathrm{IC}_{50}>1000 \mu \mathrm{M}\right)$.

\section{Effect of TMZ on cell cycle}

To investigate whether cell cycle arrest is induced in malignant glioma cells by TMZ, we performed the DNA flow cytometric analysis. As shown in Table 1, TMZ treatment $(100 \mu \mathrm{M}, 72 \mathrm{~h})$ increased the population at the G2/M phase and decreased the population at the $\mathrm{G} 1$ in all malignant glioma cells that we tested. These results indicate that $T M Z$ induces $\mathrm{G} 2 / \mathrm{M}$ arrest in malignant glioma cell lines. As predicted from the result of cell viability assay, the increase in the G2/M population was the least in T98G cells.

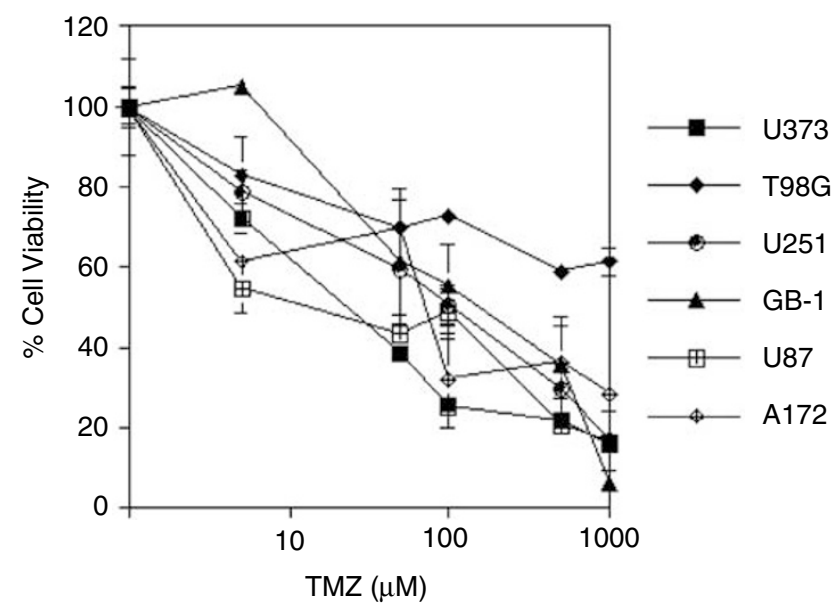

Figure 1 Effect of TMZ on cell viability of malignant glioma cells. Tumor cells were seeded at $2 \times 10^{3}$ cells per well $(0.1 \mathrm{ml})$ in 96-well flat-bottomed plates and incubated overnight at $37^{\circ} \mathrm{C}$. After exposure to $\operatorname{TMZ}(5,50,100,500$, or $1000 \mu \mathrm{M})$ for 3 days, the cells were trypsinized and the number of viable cells was counted. The viability of the untreated cells was regarded as $100 \%$. Results shown are the means \pm S.D. of three independent experiments

\section{Undetectable apoptosis in TMZ-treated U373-MG cells}

To determine whether TMZ-treated tumor cells undergo apoptosis, we performed the apoptosis detection assay. As shown in Figure 2, no significant number of apoptotic cells was detected in U373-MG cells treated with or without TMZ $(100 \mu \mathrm{M})$ for $72 \mathrm{~h}$ (Figure $2 \mathrm{a}$ or b). Cisplatin, which was used as a positive control to induce apoptosis in malignant glioma cells, ${ }^{13}$ induced apoptosis in $64.2 \%$ of U373-MG cells (Figure 2c). There was no significant apoptosis in other malignant glioma cells treated with $\mathrm{TMZ}(100 \mu \mathrm{M})$ for $72 \mathrm{~h}$ (data not shown). These results indicate that the cytotoxicity of $T M Z$ is not due to induction of apoptosis.

\section{Induction of autophagy in TMZ-treated U373-MG cells}

Recent investigations demonstrate that radiation or chemotherapeutic agents such as tamoxifen or arsenic trioxide induce autophagy, but not apoptosis in several cancer cells including malignant glioma cells. ${ }^{14-17}$ Therefore, we examined if autophagy is induced in U373-MG cells after the treatment with TMZ. After exposure to TMZ $(100 \mu \mathrm{M})$ for 3 days, U373-MG cells were collected and the ultrastructure of the cells was analyzed by electron microscopy. As shown in Figure 3, autophagosomes and secondary lysosomes were often observed in TMZ-treated U373-MG cells (Figure 3b), while untreated tumor cells exhibited few such features (Figure 3a). Most of the autophagosomes contained lamellar structures (Figure 3c) or residual digested materials (Figure 3d). These results indicate that U373-MG cells treated with $\mathrm{TMZ}$ for 3 days were in the stage of autophagic process.

\section{Development of acidic vesicular organelles (AVOs) in TMZ-treated U373-MG cells}

To identify the development of AVOs, which is characteristic of autophagy, we used the lysosomo-tropic agent, acridine orange that moves freely across biological membranes when uncharged. Its protonated form accumulates in acidic compartments, where it forms aggregates that fluoresce bright red. ${ }^{15,17}$ To detect and quantify the TMZ-induced increase in fractional volume and/or acidity of AVOs, we performed a flow cytometric analysis. As shown in Figure 4a-I and -II, TMZ increased the strength of the bright red fluorescence ( $y$-axis) in U373-MG cells from 7.81 to $38.0 \%$, indicating development of AVOs. 3-Methyladenine (3-MA, $1.0 \mathrm{mM}$ ), an inhibitor of

Table 1 Effect of TMZ on Cell Cycle

\begin{tabular}{|c|c|c|c|c|c|c|c|c|c|c|c|c|}
\hline & \multicolumn{2}{|c|}{ U373-MG } & \multicolumn{2}{|c|}{ T98G } & \multicolumn{2}{|c|}{ U251-MG } & \multicolumn{2}{|c|}{ GB-1 } & \multicolumn{2}{|c|}{ U87-MG } & \multicolumn{2}{|c|}{ A172 } \\
\hline & Control & TMZ & Control & TMZ & Control & TMZ & Control & TMZ & Control & TMZ & Control & TMZ \\
\hline $\begin{array}{l}\text { Cell cycle } \\
\text { G1 }(\%) \\
\text { S (\%) } \\
\text { G2/M (\%) }\end{array}$ & $\begin{array}{l}66.57 \\
12.36 \\
15.46\end{array}$ & $\begin{array}{c}16.3 \\
5.93 \\
62.79\end{array}$ & $\begin{array}{l}72.27 \\
10.77 \\
13.83\end{array}$ & $\begin{array}{r}66.89 \\
9.29 \\
20.86\end{array}$ & $\begin{array}{l}59.74 \\
16.04 \\
13.43\end{array}$ & $\begin{array}{c}18.1 \\
9.46 \\
63.01\end{array}$ & $\begin{array}{l}49.58 \\
16.43 \\
22.77\end{array}$ & $\begin{array}{l}28.17 \\
10.67 \\
60.57\end{array}$ & $\begin{array}{l}73.71 \\
12.26 \\
11.73\end{array}$ & $\begin{array}{r}56.78 \\
7.21 \\
30.93\end{array}$ & $\begin{array}{r}82.86 \\
5.98 \\
9.71\end{array}$ & $\begin{array}{r}42.42 \\
5.02 \\
47.97\end{array}$ \\
\hline
\end{tabular}

${ }^{a}$ For cell cycle analysis, malignant glioma cells treated with or without TMG (100 $\left.\mu \mathrm{M}\right)$ for 3 days were collected and stained with propidium iodide and analyzed in the FACScan. The percentage of cells in different phases of the cell cycle was determined by using CellFit Software 

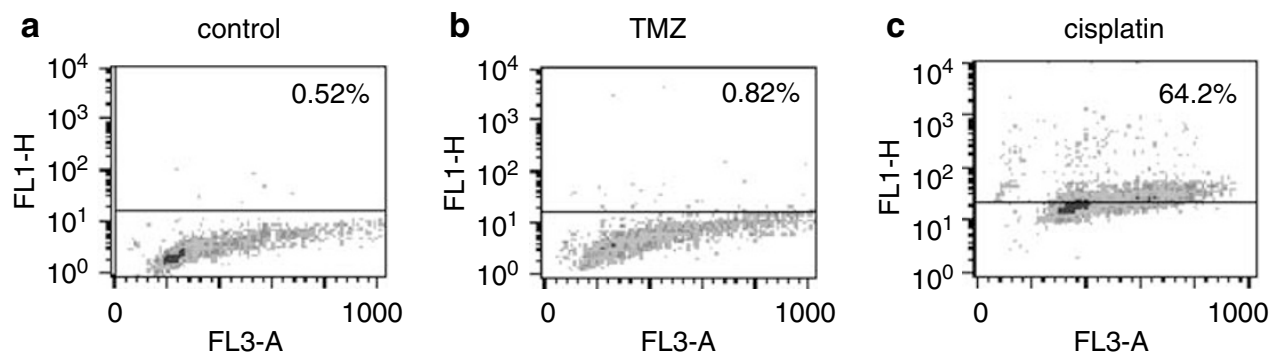

Figure 2 Flow cytometric analysis of apoptotic cells after treatment with TMZ. After the treatment for $72 \mathrm{~h}$, U373-MG cells were fixed, labeled with Br-dUTP, stained with FITC-anti-Br-dUTP antibody, and then analyzed by FACScan. The dots above the horizontal threshold line indicate the apoptotic cells. Cisplatin was used as a positive control to induce apoptosis. (a) untreated cells; (b) TMZ (100 $\mu \mathrm{M})$-treated cells, and (c) cisplatin $(5.0 \mu \mathrm{g} / \mathrm{ml})$-treated cells. Data shown are representative of three independent experiments

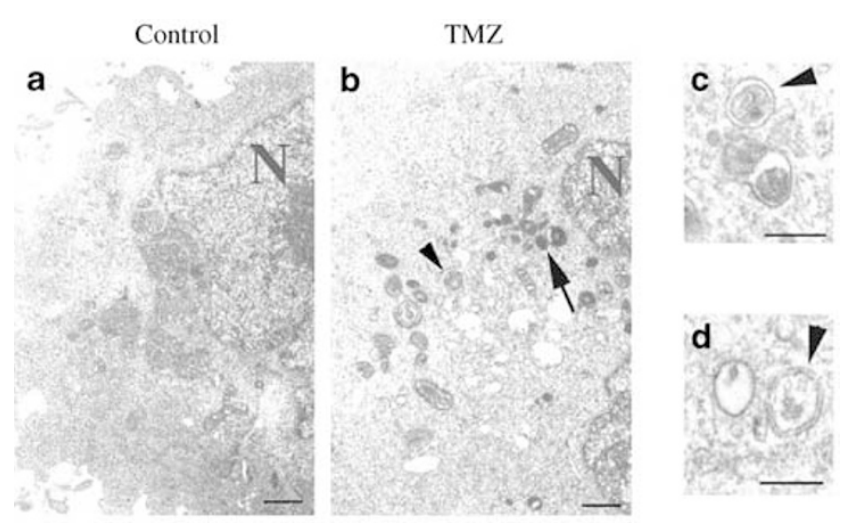

Figure 3 Ultrastructural features of TMZ-treated U373-MG cell. U373-MG cells treated with or without TMZ $(100 \mu \mathrm{M})$ for $72 \mathrm{~h}$ were harvested and fixed, and the electron microscopic observation was performed. (a) untreated cells. $\mathrm{N}$ indicates nucleus; (b) TMZ $(100 \mu \mathrm{M})$-treated cells. An arrowhead or arrow indicates autophagosome or secondary lysosomes, respectively. $\mathrm{N}$ indicates nucleus; (c) an arrowhead indicates autophagosome including lamellar structure in TMZtreated tumor cells; and (d) an arrowhead indicates autophagosome including residual digested material in TMZ-treated tumor cells. $\operatorname{Bar}(\mathbf{a}, \mathbf{b}), 5 \mu \mathrm{m}$; and $(\mathbf{c}, \mathbf{d})$, $0.5 \mu \mathrm{m}$

phosphatidylinositol-3 kinase (PI3K), which is known to inhibit autophagic sequestration, ${ }^{18-20}$ suppressed the induction of AVOs in U373-MG cells untreated or treated with TMZ (Figure 4a-III and -IV). Furthermore, bafilomycin A1 (10 nM), a vacuolar $\mathrm{H}^{+}$-ATPase inhibitor, which inhibits the fusion between autophagosome and lysosome, ${ }^{18-22}$ also suppressed the formation of AVOs (Figure 4b). 3-MA or bafilomycin A1 was to some extent toxic to cells as described previously. ${ }^{22}$ Therefore, we decreased the concentration of 3MA or bafilomycin A1 up to that did not yield any significant cell damage even after a 3-day culture. We repeated the same experiments three times and a similar tendency was detected and the effect was statistically significant $(P<0.01)$. These results indicate that the TMZ-induced increase of the bright red fluorescence is attributable to the development of AVOs associated with autophagy. Development of AVOs in other malignant glioma cells treated with TMZ was also detected (data not shown).

\section{Involvement of LC3 in TMZ-treated U373-MG cells}

The microtubule-associated protein 1 light-chain 3 (LC3) is essential for amino-acid starvation-induced autophagy and associated with the autophagosome membrane. ${ }^{18,19,23}$ To assess if LC3 is involved in TMZ-induced autophagy, we established the U373-MG clone transfected with LC3 fused to green fluorescent protein (GFP-LC3). Under a fluorescence microscope, GFP-LC3 transfected U373-MG cells showed diffuse distribution of green fluorescence in the absence of TMZ (Figure 5a-I). In contrast, treatment with TMZ increased a punctate pattern in number and fluorescence intensity, representing autophagic vacuoles (Figure 5a-II), indicating that LC3 is recruited in TMZ-induced autophagy. Amino-acid starvation also induced similar large dots of LC3 staining in U373-MG cells (data not shown). As shown in Figure 5a-III and -IV, the appearance of a punctate pattern of LC3 was suppressed by $1.0 \mathrm{mM} 3-\mathrm{MA}$. On the other hand, another autophagy inhibitor, bafilomycin $\mathrm{A} 1(10 \mathrm{nM})$ did not suppress localization of LC3 induced by TMZ (Figure 5b). To quantify the induction of cells expressing LC3 aggregation, we counted 200 GFP-positive cells for each treatment. As shown in Figure $5 \mathrm{c}, 52 \%$ of U373-MG cells treated with TMZ $(100 \mu \mathrm{M})$ for 3 days showed LC3 aggregation, while these autophagic features were detected in $26 \%$ of untreated U373-MG cells. The incidence of LC3 aggregation in TMZ-treated U373-MG cells was decreased to $21 \%$ by $3-\mathrm{MA}(1.0 \mathrm{mM})$, but was not affected by bafilomycin $\mathrm{A} 1(10 \mathrm{nM})$. The number of cells expressing a punctate pattern of LC3 was significantly increased in tumor cells treated with $\mathrm{TMZ}$ alone or its combination with bafilomycin A1 compared to the control or 3-MA alone $(P<0.01)$. These findings indicate that bafilomycin A1 inhibits autophagy after autophagosome membrane association of LC3. The mRNA expression levels of LC3 increased during amino-acid starvation. ${ }^{24}$ Therefore, we determined if $T M Z$ increases the expression level of LC3 mRNA in U373-MG cell. As shown in Figure 5d, LC3 mRNA expression was increased by 3.0-fold after the treatment with $\mathrm{TMZ}(100 \mu \mathrm{M})$ for 3 days and the increase was significant when compared to the control $(P<0.01)$. 3-MA $(1.0 \mathrm{mM})$ inhibited the increase of LC3 mRNA in tumor cells treated with TMZ, while an increased level of LC3 mRNA following TMZ treatment was not affected by bafilomycin $A 1(10 \mathrm{nM})$. These results indicate that $T M Z$ treatment increases $L C 3$ expression and forms LC3-associated autophagosome in U373-MG cells. 3-MA inhibits TMZ-induced autophagy prior to autophagosome membrane association of LC3, while bafilomycin A1 suppresses TMZ-induced autophagy after localization of LC3 in autophagosome. 

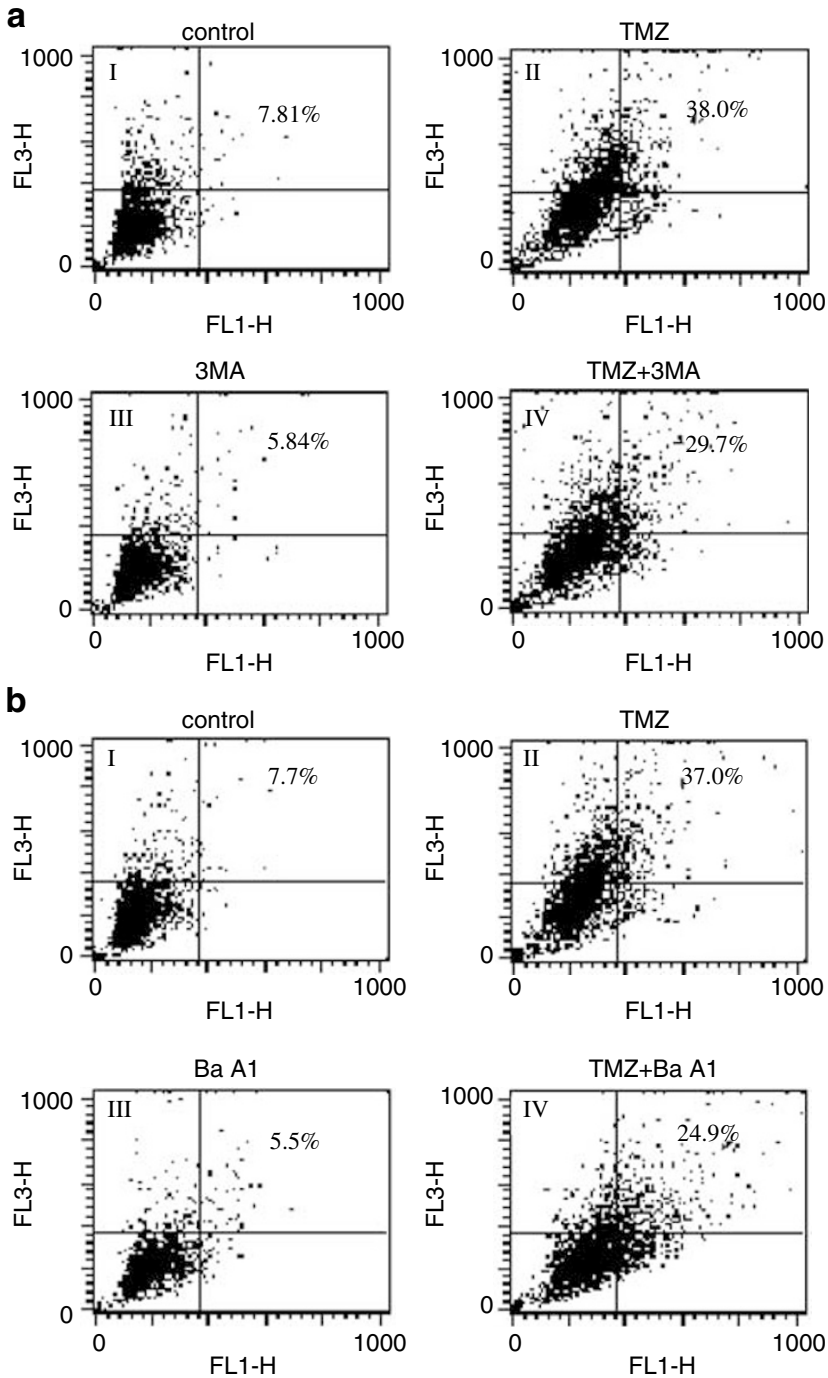

Figure 4 Development of AVO in TMZ-treated U373-MG cells. Detection of green and red fluorescence in acridine orange-stained cells using FACS analysis. (a) (a) untreated cells; (b) cells treated with TMZ $(100 \mu \mathrm{M})$ for $72 \mathrm{~h}$; (c) cells treated with 3-MA $(1.0 \mathrm{mM})$ for $48 \mathrm{~h}$; and (d) cells treated with TMZ $(100 \mu \mathrm{M})$ for $24 \mathrm{~h}$, and further treated with 3-MA $(1.0 \mathrm{mM})$ for $48 \mathrm{~h}$. (b) (a) untreated cells; (b) cells treated with TMZ $(100 \mu \mathrm{M})$ for $72 \mathrm{~h}$; (c) cells treated with bafilomycin A1 $(10 \mathrm{nM})$ for $48 \mathrm{~h}$; and (d) cells treated with TMZ $(100 \mu \mathrm{M})$ for $24 \mathrm{~h}$, and further treated with bafilomycin $\mathrm{A} 1(10 \mathrm{nM})$ for $48 \mathrm{~h}$. FL1-H indicates green color intensity, while FL3-H shows red color intensity. Data shown are representative of three independent experiments

\section{Effect of 3-MA or bafilomycin A1 on TMZ-induced cytotoxicity}

To investigate if inhibition of autophagy at different steps affects the cytotoxicity of TMZ, U373-MG cell were treated with $100 \mu \mathrm{M} \mathrm{TMZ}$ for 3 days in the presence of 3-MA or bafilomycin $A 1$. As shown in Figure $6 a$, the cell viability of U373-MG cells treated with TMZ was increased from 37 to $52 \%$ by $3-\mathrm{MA}(1.0 \mathrm{mM})(P<0.05)$. On the other hand, in the presence of bafilomycin A1 (10 nM), cell viability of U373-MG cells was further decreased from 37 to $19 \%(P<0.01)$. However, bafilomycin A1 did not sensitize tumor cells to TMZ when autophagy was blocked by treatment with 3-MA.
These findings suggest a direct implication for the accumulation of autophagic vacuoles in the combination effect of TMZ and bafilomycin A1. To determine if the antitumor effect of $\mathrm{TMZ}$ alone or its combination with bafilomycin $\mathrm{A} 1$ is transient, we counted the number of viable cells treated with $T M Z$ and/or bafilomycin $A 1$ up to 10 days after initiation of treatment. As shown in Figure $6 \mathrm{~b}$, the viable cell number of tumor cells treated with $100 \mu \mathrm{M} \mathrm{TMZ}$ alone did not decrease below the initial cell number and treated tumor cells began proliferating on day 7 . This finding raises the possibility that TMZ-induced autophagy might be reversible and defensive to protect tumor cells from cell death. When tumor cells were treated with TMZ and bafilomycin A1, the viable cell number of treated tumor cells decreased below the initial cell number on day 7 , indicating that the majority of tumor cells died (Figure 6b). And the proliferation of tumor cells treated with TMZ and bafilomycin A1 was suppressed at least up to 10 days after initiation of treatment. To examine if decreased cell viability induced by bafilomycin $\mathrm{A} 1$ is due to induction of apoptosis, we further performed apoptosis detection assay. As shown in Figure 6c, TMZ in the presence of bafilomycin A1 induced apoptosis in $13.4 \%$ of U373-MG cells 3 days after exposure to TMZ. On the other hand, tumor cells treated with bafilomycin A1 alone showed $<1 \%$ apoptotic cells $(P<0.01)$. When associated with $\mathrm{TMZ}$ treatment, bafilomycin $\mathrm{A} 1$ decreased the cell viability to $19 \%$ (Figure $6 a$ ). At the same time this treatment induced apoptosis in $13.4 \%$ of U373-MG cells (Figure 6c). This discrepancy might arise as a consequence of the method used to analyze cell viability and apoptosis, respectively. As another possibility, based on the result showing that the majority of treated tumor cells died within a week (Figure 6b), it might be too early to detect massive apoptotic cell death on day 3 . These results indicate that application of an autophagy inhibitor, bafilomycin A1, after LC3 localization enhances the antitumor effect of TMZ against malignant glioma cells by induction of apoptosis.

\section{Characterization of TMZ/bafilomycin A1-induced cell death}

To characterize the mechanisms by which bafilomycin $A 1$ enhances the effect of TMZ on malignant glioma cells by inhibiting autophagy at a late stage, the following experiments were performed. First, we determined if mitochondrial membrane integrity is damaged by TMZ and/or bafilomycin A1. As shown in Figure $7 \mathrm{a}$, treatment with $\operatorname{TMZ}(100 \mu \mathrm{M})$ for 3 days induced loss of membrane potential from 10.3 to $20.7 \%$ and the mitochondrial damage was increased to $24.3 \%$ by bafilomycin A1. Second, we examined whether apoptosisexecutioner, caspase- 3 is activated by TMZ and/or bafilomycin $\mathrm{A} 1$. Figure $7 \mathrm{~b}$ showed that combination of $T M Z$ and bafilomycin $A 1$ decreased bioluminescence to $50 \%$ of the control, while inhibition of bioluminescence was not detected in U373-MG cells treated with TMZ alone or bafilomycin A1 alone. The result of caspase-3 activity assay revealed that combining TMZ with bafilomycin A1 activated caspase-3 significantly compared to each treatment $(P<0.01)$. Recently, it has been demonstrated that some apoptotic cell death pathways have a sign of lysosomal membrane permeabiliza- 
a
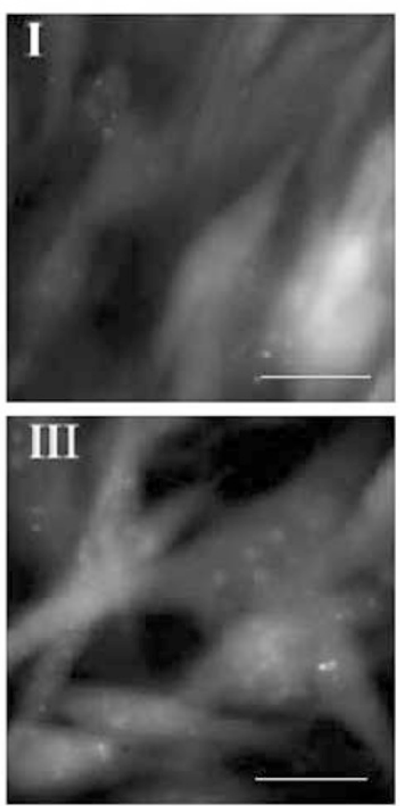

3-MA
TMZ 100
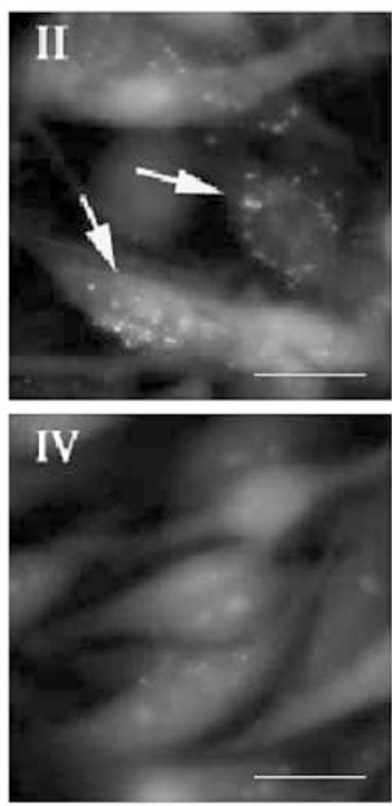

$\mathrm{TMZ}+3 \mathrm{MA}$ b
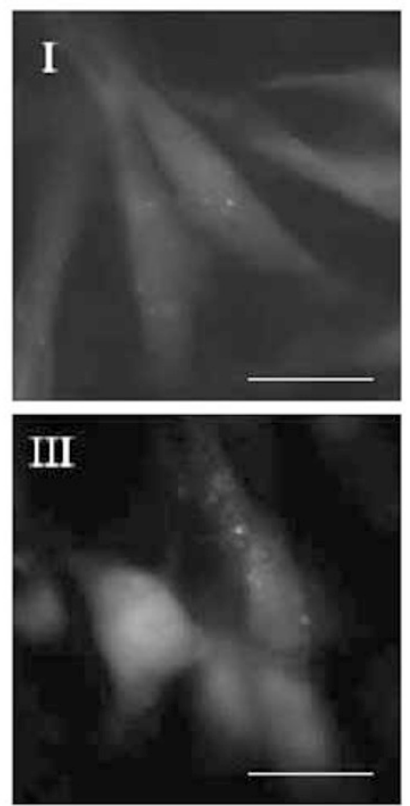

Bafilomycin
TMZ 100
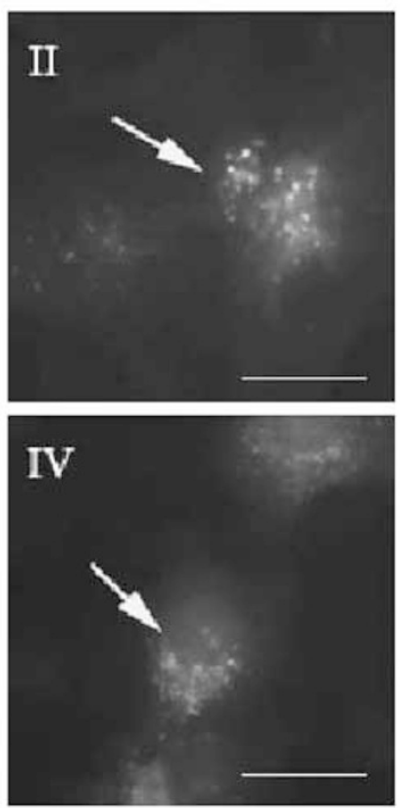

TMZ+Bafilomycin

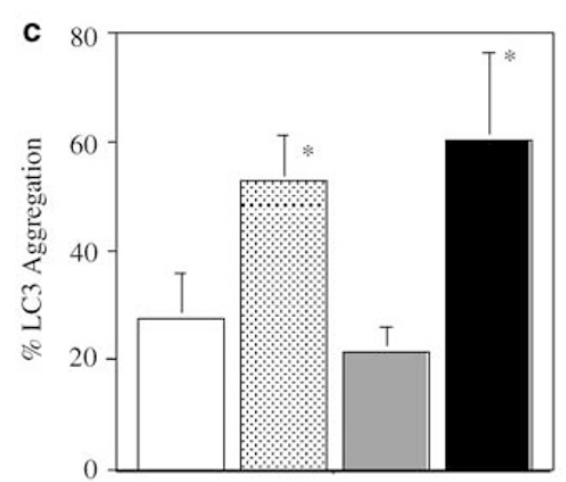

d

\section{Control TMZ TMZ+3MA TMZ+}

Bafilomycin

LC3

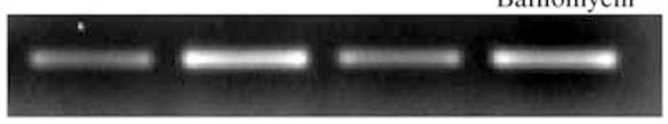

TMZ

TMZ+3MA

GAPDH

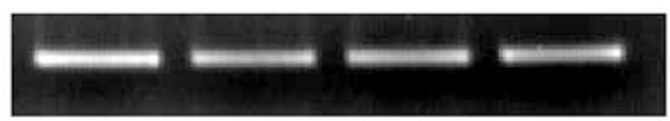

TMZ+Bafilomycin

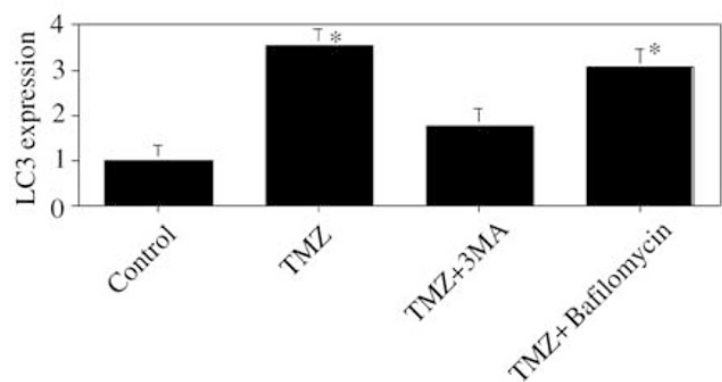

Figure 5 Involvement of LC3 in TMZ-induced autophagy. (a) and (b) Punctuate signal of GFP- LC3 in TMZ-treated U373-MG cells. (a) (a) untreated cells; (b) cells treated with TMZ $(100 \mu \mathrm{M})$ for $72 \mathrm{~h}$; (c) cells treated with 3-MA (1.0 mM) for $48 \mathrm{~h}$; and (d) cells treated with TMZ (100 $\mu \mathrm{M})$ for $24 \mathrm{~h}$, and further treated with 3-MA (1.0 mM) for $48 \mathrm{~h}$. (b) (a) untreated cells; (b) cells treated with TMZ (100 $\mu \mathrm{M}$ ) for $72 \mathrm{~h}$; (c) cells treated with bafilomycin A1 (10 nM) for $48 \mathrm{~h}$; and (d) cells treated with TMZ (100 $\mu \mathrm{M}$ ) for $24 \mathrm{~h}$, and further treated with bafilomycin A1 $(10 \mathrm{nM})$ for $48 \mathrm{~h}$. Cells were examined by fluorescence microscopy. (c) Quantification of cells expressing LC3aggregation after TMZ treatment. The percentage of LC3 aggregated cells was quantitated by counting the number of the cells showing the punctate pattern of GFP-LC3 in 200 GFP-positive cells. Results shown are the means \pm S.D. of three independent experiments. ${ }^{\star} P<0.01$. (d) Semiquantitative RT-PCR analysis of LC3 mRNA in U373-MG cells. Control, untreated cells; TMZ, cells treated with TMZ (100 $\mu \mathrm{M})$ for 3 days; TMZ + 3-MA, cell treated with TMZ (100 $\mu \mathrm{M})$ for $24 \mathrm{~h}$, and further treated with 3-MA (1.0 mM) for $48 \mathrm{~h}$; TMZ + bafilomycin A1, cell treated with TMZ $(100 \mu \mathrm{M})$ for $24 \mathrm{~h}$, and further treated with bafilomycin A1 (10 nM) for $48 \mathrm{~h}$. RNA was reverse transcribed and amplified with specific primer for hLC3 or GAPDH, as described in Materials and Methods. Data shown are representative of three independent experiments. The relative expression levels of LC3 normalized by GAPDH are shown in the lower panel. Results shown are the means $\pm S$.D. of three independent experiments. ${ }^{*} P<0.01$

tion such as the release of cathepsin B from the lysosomal lumen, followed by signs of apoptosis including caspase activation. ${ }^{25}$ Therefore, we finally determined if combination of $T M Z$ and bafilomycin $A 1$ released cathepsin $B$ from lysosome. As shown in Figure 7c, cathepsin B colocalized with Lamp-1 (the lysosomal membrane marker) in untreated U373-MG cells (control). TMZ caused an increase in lysosomal volume, but cathepsin B was retained in lysosomes. When bafilomycin A1 was added to U373-MG cells treated with $T M Z$, the size and number of lysosomes became 
smaller. These findings were consistent with the results of AVO development (Figure 4b). Interestingly, cathepsin B was released from lysosomes by treatment with $T M Z$ and bafilomycin $A 1$, although $T M Z$ alone or bafilomycin $A 1$ alone did not release cathepsin $B$. These results indicate that combination of $T M Z$ and bafilomycin $A 1$ induces apoptosis via activation of caspase- 3 and mitochondrial and lysosomal
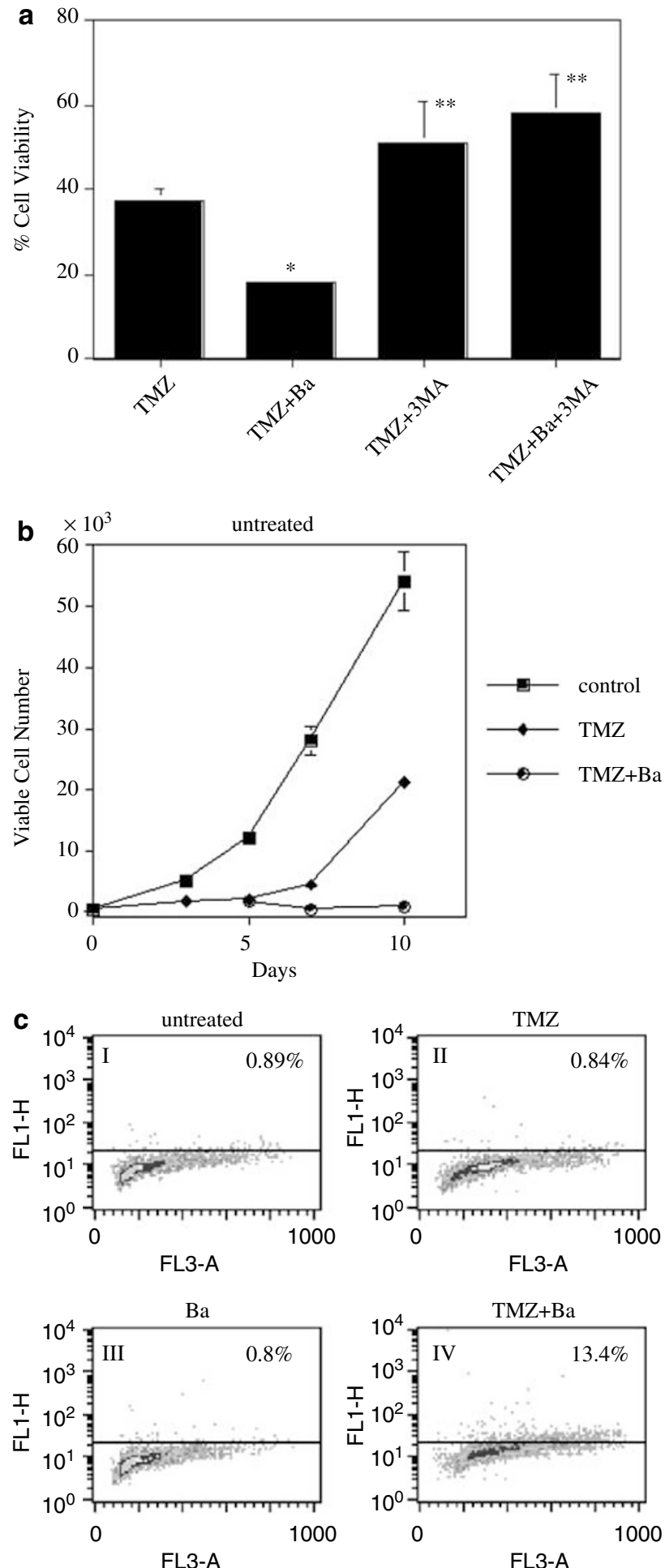

membrane permeabilization may be a critical step of this apoptosis.

\section{Discussion}

In the present study, we demonstrate for the first time that $\mathrm{TMZ}$ induces autophagy, but not apoptosis in malignant glioma cells. We further demonstrate that the pharmacological inhibition of autophagy at different steps has different outcomes on TMZ-induced autophagy. 3-MA inhibits LC3 localization to the autophagosomal membrane and subsequently rescues tumor cells from cell death (Figure 8 ). On the other hand, bafilomycin A1 inhibits autophagy, but LC3 localization is not suppressed. Accumulation of autophagic vacuoles without fusing with lysosomes induces mitochondrial and lysosomal membrane permeabilization, resulting in induction of apoptosis via activation of caspase-3 (Figure 8). These findings suggest that autophagy is a main part of TMZinduced cytotoxicity and that inhibition of the autophagic process significantly influences the antitumor effect of TMZ. Therefore, agents that inhibit autophagy at a late stage like bafilomycin A1, may be promising candidates to combine TMZ.

It has long been known that 3-MA inhibits autophagy, ${ }^{26}$ and it was recently found to be an inhibitor of PI3K. ${ }^{27} \mathrm{PI} K \mathrm{~K}$ is a conserved family of lipid kinases that catalyze the phosphorylation of the position 3 of the inositol ring of phosphoinositides. $^{28-30}$ They produce lipids that are involved in cell proliferation, differentiation, apoptosis, autophagy, cytoskeletal organization, and membrane trafficking. Three classes of PI3K have been defined so far. Class I PI3K is involved in inhibitory effect on autophagy, while the class III PI3K is involved in the sequestration of cytoplasmic material in autophagy. ${ }^{31}$ Therefore, we suggest that the effect of 3-MA on TMZ-induced autophagy may be due to inhibition of the class III PI3K. Bafilomycin A1 is a specific inhibitor of the lysosomal protein pump (vacuolar $\mathrm{H}^{+}$-ATPase). ${ }^{21,22}$ ATP is required at all steps of autophagy. ${ }^{21}$ In agreement with this finding, bafilomycin A1 suppresses autophagy by inhibiting fusion between autophagosomes and lysosomes. This inhibitory effect may be due to a requirement that the lysosome be acidified for fusion with the autophagosome. ${ }^{20}$

Figure 6 Effect of 3-MA or bafilomycin A1 on TMZ-induced cytotoxicity. (a) Effect of 3-MA or bafilomycin A1 on the cell viability of TMZ-treated U373-MG cells. At $24 \mathrm{~h}$ after exposure to TMZ $(100 \mu \mathrm{M}), 3-\mathrm{MA}(1.0 \mathrm{mM})$ or bafilomycin A1 $(10 \mathrm{nM})$ was added and cultured for additional $48 \mathrm{~h}$. The cells were trypsinized and the number of viable cells was counted. The viability of the untreated cells was regarded as $100 \%$. Results shown are the means \pm S.D. of three independent experiments. ${ }^{\star} P<0.01,{ }^{\star *} P<0.05$. (b) Viable cell number of U373MG cells treated with TMZ $(100 \mu \mathrm{M})$ and/or bafilomycin A1 (10 nM). After tumor cells were treated as described above, the viable cell number was counted up to 10 days. Results shown are the means \pm S.D. of three independent experiments. (c) Effect of bafilomycin A1 on induction of apoptosis in TMZ-treated U373-MG cells. At $24 \mathrm{~h}$ after exposure to TMZ $(100 \mu \mathrm{M})$, bafilomycin $\mathrm{A} 1(10 \mathrm{nM})$ was added and cultured for additional $48 \mathrm{~h}$. Then flow cytometric analysis of apoptotic cells was performed as described above. The dots above the horizontal threshold line indicate the apoptotic cells. (a) untreated cells; (b) cells treated with TMZ $(100 \mu \mathrm{M})$ for $72 \mathrm{~h}$; (c) cells treated with bafilomycin $\mathrm{A} 1(10 \mathrm{nM})$ for $24 \mathrm{~h}$; and $(\mathrm{d})$ cells treated with TMZ $(100 \mu \mathrm{M})$ for $24 \mathrm{~h}$, and treated with bafilomycin $\mathrm{A} 1$ (10 nM) for additional $48 \mathrm{~h}$. Data shown are representative of three independent experiments 
Pretreatment with bafilomycin A1 reduces the frequency of lysosomal release of cathepsin B induced by lysosomotropic amines such as hydroxychloroquine. ${ }^{25}$ In the present study,

a
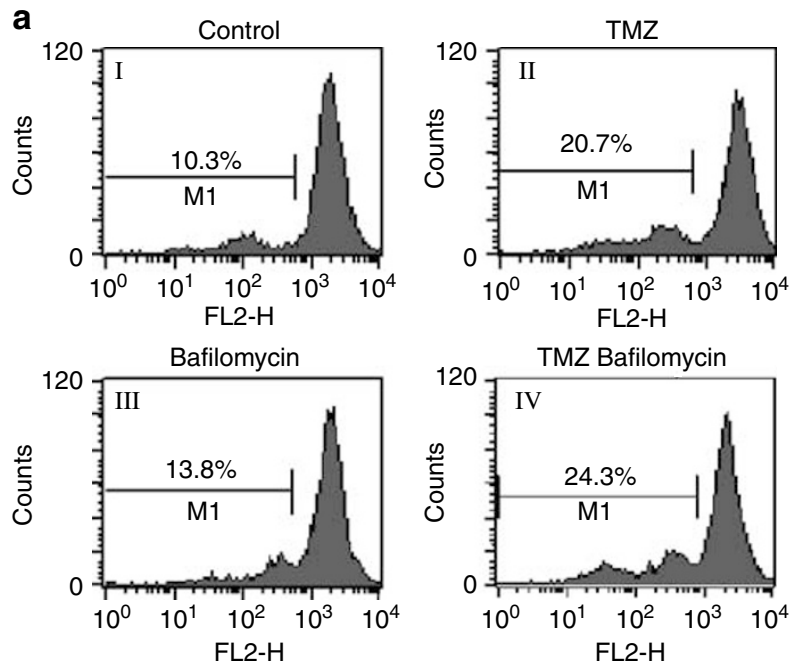

b

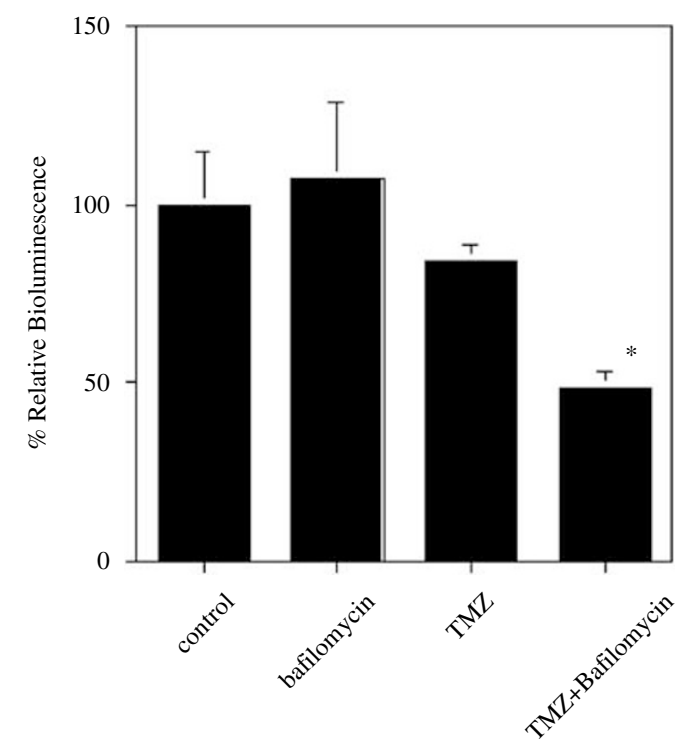

C
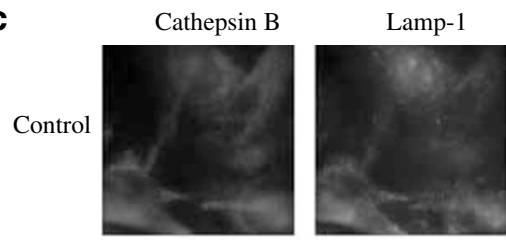

Merge
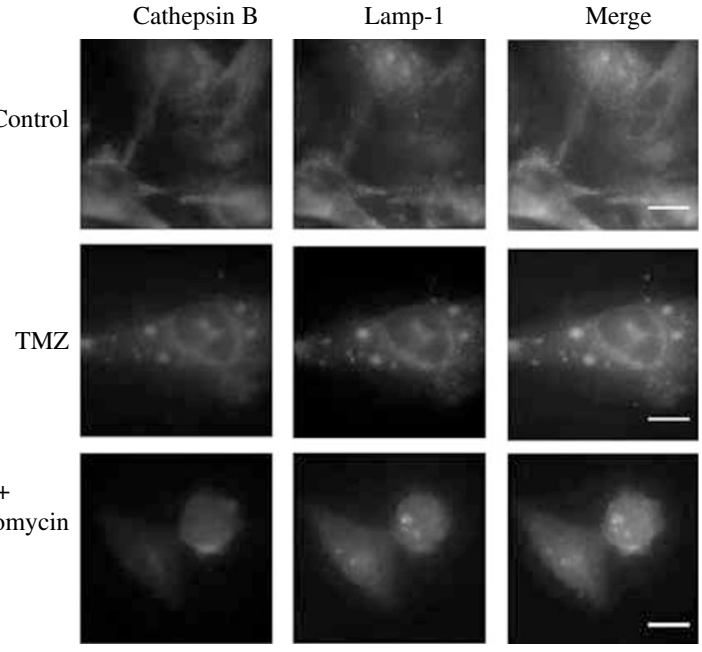

Temozolomide

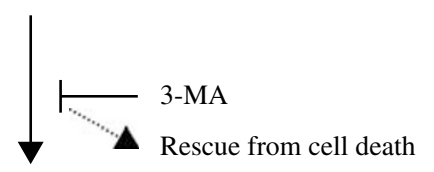

Localization of LC3 on autophagosome

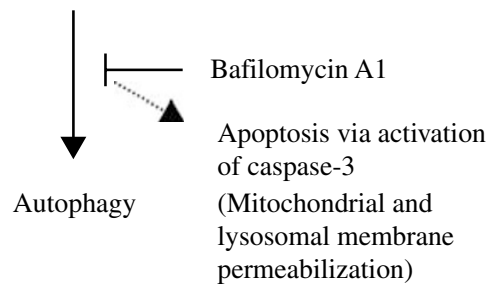

Figure 8 TMZ-induced autophagy in malignant glioma cells. The pharmacological inhibition of autophagy at different steps has different outcomes on TMZinduced cytotoxicity. When autophagy is inhibited by 3-MA before autophagosome membrane association of LC3 occurs, tumor cells are rescued from autophagy. Treatment with TMZ in the presence of bafilomycin $A 1$ accumulates autophagic vacuoles expressing LC3 and induces apoptosis via activation of caspase-3 with mitochondrial and lysosomal membrane permeabilization

however, cathepsin B was released by combining $T M Z$ with bafilomycin $A 1$, although $T M Z$ alone or bafilomycin $A 1$ alone did not affect the release of cathepsin $B$. These findings suggest that the presence of bafilomycin A1 may correlate accumulation of autophagic vacuoles induced by $T M Z$ with perturbation of lysosomal function, leading to induction of apoptosis via activation of caspase-3. When radiation- or arsenic trioxide-induced autophagy was inhibited by bafilomycin A1, the survival of tumor cells was decreased through induction of apoptosis, ${ }^{15,17}$ which corresponds to our result. Therefore, inhibition of autophagy at this late stage may stimulate some signals to trigger mitochondrial and lysosomal membrane permeabilization, and subsequently induce apoptotic cell death.

Autophagy is a term used to describe the process of protein recycling, typically observed in hepatic cells following aminoacid deprivation. ${ }^{20,32}$ It begins with sequestration of cytoplasmic organelles in a membrane vacuole called autophagosome. Autophagosomes then fuse with lysosomes, where the material inside is degraded and recycled. By this process, autophagy recycles molecules for biosynthetic or metabolic reactions. The morphology and regulation of autophagy induced by amino-acid starvation are extensively investi-

Figure 7 Characterization of TMZ/bafilomycin A1-induced cell death. U373MG cells were treated with TMZ $(100 \mu \mathrm{M})$ for $24 \mathrm{~h}$, and/or further treated with bafilomycin $\mathrm{A} 1(10 \mathrm{nM})$ for $48 \mathrm{~h}$. (a) Disruption of mitochondrial membrane potential in U373-MG cells by TMZ and bafilomycin A1. Mitochondrial membrane potential was measured by TMRE fluorescence using FACS. After treatment with TMZ and/or bafilomycin A1, tumor cells were collected and stained with TMRE as described in Materials and Methods. Data shown are representative of three independent experiments. (b) Detection of caspase-3 activity. Using the CleavaLite $^{\mathrm{TM}}$ Caspase-3 activity assay kit, we determined if TMZ and/or bafilomycin $A 1$ activate caspase-3. Results shown are the means \pm S.D. of three independent experiments. ${ }^{*} P<0.01$. (c) Translocation of cathepsin $B$ induced by TMZ and bafilomycin A1. U373-MG cells treated with TMZ and/or bafilomycin A1 were stained for immunofluorescence detection of the lysosomal membrane (Lamp-1) and cathepsin B. Data shown are representative of three independent experiments. Bars, $5 \mu \mathrm{m}$ 
gated. ${ }^{20}$ In cancer research, however, autophagy is a novel concept and the genes involved in the process mainly remain unclear. In tumorigenesis, the signaling control of autophagy may depend upon the activity of tumor suppressor genes such as PTEN in colon cancer cells and Beclin-1 in breast cancer cells. ${ }^{33,34}$ Recent investigations suggest that autophagy plays a defensive role in cancer therapy. ${ }^{15,35}$ In general, autophagic degradation is reduced in cancer cells than in their normal counterparts. ${ }^{35}$ Once cancer cells are exposed to radiation or chemotherapeutic agents, a high rate of autophagy is observed in cancer cells. ${ }^{15,36}$ To adapt to adverse conditions induced by cancer therapy, cancer cells trigger reversible autophagic process that sequesters and degrades unnecessary molecules for their survival. Therefore, it has been suggested that autophagy plays a crucial role not only in degradative pathway, but also in self-defense mechanism of cancer for treatment. ${ }^{35}$ In the present study, malignant glioma cells treated with $\mathrm{TMZ}$ at a clinically achievable concentration began proliferating a week after exposure to TMZ. Therefore, we suggest that TMZ-induced autophagy might provide a mechanism of self-defense for cancer cells. When such autophagy is induced by cancer therapy, inhibition of autophagy by bafilomycin A1 may enhance the antitumor effect of cancer treatment that induces such autophagy.

In some cases, autophagy plays a key role in the elimination of cancer cells by triggering a nonapoptotic cell death program. ${ }^{14,37}$ This type of autophagy is irreversible and is referred to type II programmed cell death or autophagic cell death, in contrast to apoptosis, which is designated as type I programmed cell death. ${ }^{37,38}$ More recently, we have demonstrated that arsenic trioxide induces autophagic cell death in malignant glioma cells. ${ }^{17}$ At a clinically achievable concentration of arsenic trioxide $(2 \mu \mathrm{M})$, the viable cell number of treated tumor cells decreased below the initial cell number. A vast majority of treated tumor cells died within a week after the treatment. When autophagic cell death is induced, autophagy functions as a self-destructive mechanism in cancer cells. ${ }^{35}$ In contrast with autophagy in self-defense, the stimulation of autophagy in self-destruction enhances therapeutic efficacy. Interestingly, bafilomycin A1 enhances the effect of arsenic trioxide by induction of apoptosis, ${ }^{17}$ as it functioned for TMZinduced autophagy. Depending on type of autophagy following cancer therapy, the autophagic process can be exploited to eradicate cancer cells. To date, however, very little is known about the molecular pathways that regulate autophagy in cancer.

In conclusion, our findings show that autophagy, but not apoptosis is induced in malignant glioma cells by the treatment with TMZ. Depending on where autophagy is suppressed by an inhibitor, two opposite outcomes occur following TMZ treatment. Inhibition of autophagy at a late stage could increase the therapeutic efficacy of $T M Z$ for malignant glioma cells.

\section{Materials and Methods}

\section{Tumor cell lines}

Human malignant glioma U87-MG, A172, T98G, U373-MG cells were purchased from ATCC (American Tissue Culture Collection, Rockville,
MD, USA). Human malignant glioma GB-1 and U251-MG cells were kindly gifted by Dr. Tatsuo Morimura (National Utano Hospital, Kyoto, Japan), and Dr. Akiko Nishiyama (University of Connecticut, Storrs, CT, USA), respectively. Cells were cultured in Dulbecco's modified Eagle's medium (DMEM, GIBCO BRL, Grand Island, NY, USA) supplemented with $10 \%$ fetal bovine serum (GIBCO BRL), $4 \mathrm{mM}$ glutamine, $100 \mathrm{U} / \mathrm{ml}$ penicillin and $100 \mu \mathrm{g} / \mathrm{ml}$ streptomycin.

\section{Reagents}

Temozolomide (TMZ, 3,4-dihydro-3-methyl-4-oxoimidazo [5,1-d]-as-tetrazine-8-carboxamide) was kindly supplied by the Schering-Plough Research Institute (Kenilworth, NJ, USA) and was dissolved in DMSO (Sigma Chemical Co., St. Louis, MO, USA). Acridine orange was obtained from Polysciences, (Warrington, PA, USA). 3-MA and bafilomycin A1 were purchased from Sigma Chemical Co. (St. Louis, MO, USA).

\section{Cell viability assay}

The cytotoxic effect of TMZ on malignant glioma cell lines was determined by using a trypan blue dye-exclusion assay as described previously. ${ }^{39}$ Tumor cells were seeded at $2 \times 10^{3}$ cells/well $(0.1 \mathrm{ml})$ in 96 -well flatbottomed plates and incubated overnight at $37^{\circ} \mathrm{C}$. After exposure to TMZ $(5,50,100,500$, or $1000 \mu \mathrm{M})$ for 3 days, the cells were trypsinized and the number of viable cells was counted. The viability of untreated cells was regarded as $100 \%$.

\section{Cell cycle analysis}

For cell cycle analysis, tumor cells treated with or without TMZ $(100 \mu \mathrm{M})$ for 3 days were trypsinized, stained with propidium iodide by using the Cellular DNA Flow Cytometric Analysis Reagent Set (Boehringer Mannheim, Indianapolis, IN, USA), and analyzed for DNA content by using the FACScan (Becton Dickinson, San Jose, CA, USA) as previously described. ${ }^{39}$ Data were analyzed by Cell Quest software (Becton Dickinson). Using pulse processing gated dead cells out.

\section{Apoptosis detection assay}

Apoptosis of TMZ-treated tumor cells was detected using the APO-BRDU kit (Pharmingen, San Diego, CA, USA), according to the manufacturer's instructions as described previously. ${ }^{39}$ Briefly, the $3^{\prime}$-hydroxyl ends of the DNA in apoptotic cells were labeled with bromolated deoxyuridine triphosphate nucleotides (Br-dUTP) by terminal deoxynucleotidyl transferase, and the incorporated Br-dUTP was stained with a fluorescent isothiocyanate (FITC)-labeled anti-Br-dUTP monoclonal antibody. After DNA was stained with propidium iodide, the cells were analyzed using the FACScan.

\section{Electron microscopy}

To morphologically demonstrate the induction of autophagy in TMZtreated tumor cells, we performed the ultrastructural analysis as described previously. ${ }^{17}$ The cells treated with or without TMZ $(100 \mu \mathrm{M})$ for $72 \mathrm{~h}$ were harvested by trypsinization, washed twice with PBS and fixed with ice-cold glutaraldehyde ( $3 \%$ in $0.1 \mathrm{M}$ cacodylate buffer, $\mathrm{pH} 7.4$ ) for $30 \mathrm{~min}$. After washing in PBS the cells were postfixed in $\mathrm{OsO}_{4}$ and embedded in Epon; $0.1 \mathrm{~mm}$ thin sections were stained with uranyl acetate/lead citrate (Fluka) and viewed in a Philips EM 400 electron microscope. 


\section{Detection and quantification of acidic vesicular organelles (AVOs) with acridine orange}

Autophagy is the process of sequestrating cytoplasmic proteins into the lytic component and characterized by the formation and promotion of acidic vesicular organelles (AVOs). To detect and quantify the AVO in TMZ-treated cells, we performed the vital staining with acridine orange. In acridine orange-stained cells, the cytoplasm and nucleolus fluoresce bright green and dim red, whereas acidic compartments fluoresce bright red as described previously. ${ }^{15,17}$ The intensity of the red fluorescence is proportional to the degree of acidity and/or the volume of the cellular acidic compartment. Therefore, we could measure a change in the degree of acidity and/or the fractional volume of their cellular acidic compartment. 3 days after exposure to TMZ, cells were stained with acridine orange at a final concentration of $1 \mu \mathrm{g} / \mathrm{ml}$ for a period of $15 \mathrm{~min}$, removed from the plate with trypsin-EDTA, and collected in phenol red-free growth medium. To inhibit autophagy, 1.0 mM 3-MA or $10 \mathrm{nM}$ bafilomycin $\mathrm{A} 1$ was added next day after addition of TMZ. Green $(510-530 \mathrm{~nm})$ and red $(>650 \mathrm{~nm})$ fluorescence emission from $10^{4}$ cells illuminated with blue $(488 \mathrm{~nm})$ excitation light was measured with a FACSCalibur from Becton Dickinson using CellQuest soft-ware.

\section{Involvement of microtubule-associated protein LC3}

LC3 is a mammalian homologue of Apg8p/Aut7p essential for autophagy in yeast ${ }^{18}$ and is recruited to the autophagosome membrane in the Apg5dependent manner. ${ }^{19}$ Therefore, autophagosome membrane association of LC3 is a specific marker for autophagy. ${ }^{18,19,23}$ Recently, the green fluorescent protein (GFP)-tagged LC3 expressing cells were used to demonstrate induction of autophagy. ${ }^{18,19,23}$ GFP-LC3 cells presented a diffuse distribution under control, while a punctate pattern of GFP-LC3 was increased in number and fluorescence intensity by autophagy. Therefore, using the GFP-LC3 expression vector kindly supplied by Dr. T Yoshimori and Dr. N Mizushima (National Institute for Basic Biology, Okazaki, Japan), U373-MG cells expressing GFP-LC3 were established. Transfection was performed on $100-\mathrm{mm}$ plates with $10 \mu \mathrm{g}$ plasmid DNA/plate with GenePorter (Gene Therapy System INC., San Diego, CA, USA) according to the manufacturer's instructions. After overnight exposure, cells were washed three times with PBS and cultured in complete medium. At $48 \mathrm{~h}$ after the medium change, cells were selected in medium containing $400 \mu \mathrm{g} / \mathrm{ml}$ of $\mathrm{G} 418$ (GIBCO BRL) and G-418 resistant clones were established. To detect the localization of LC3, GFP-LC3-transfected U373MG cells were cultured on the chamber slide dish (Fisher Inc.). After exposure to TMZ for 3 days, cells were fixed in 1\% paraformaldehyde and analyzed by fluorescence microscopy. Bafilomycin A1 or 3-MA was used to inhibit autophagy.

\section{RT-PCR analysis for LC3 mRNA expression}

The expression of LC3 mRNA in U373-MG cell treated with or without TMZ was analyzed by semiquantitative RT-PCR amplification that we have recently described. ${ }^{40}$ The correlation between band intensity and dose of cDNA templates was linear under the conditions described below. Total RNA from U373-MG cells was isolated using the RNA Isolation Kit (Qiagen Inc., Valencia, CA, USA). First-strand CDNA was synthesized with total RNA $(0.5 \mu \mathrm{g})$ using the ProSTAR ${ }^{\mathrm{TM}}$ First Strand RT-PCR Kit (Invitrogen, Carlsbad, CA, USA). A volume of $2 \mu$ of $C D N A$ reaction was amplified by PCR kit (Invitrogen) using primers hLC3-5 (5'-ATGCCGTCGGAGAAGACCTT-3') and LC3-3 (5'-TTACACTGACAATTTCATCCCG-3') as described previously. ${ }^{24}$ The thermal cycle profile was $95^{\circ} \mathrm{C}$ for $30 \mathrm{~s}$, $55^{\circ} \mathrm{C}$ for $30 \mathrm{~s}$, and $70^{\circ} \mathrm{C}$ for $1 \mathrm{~min}$ for 25 cycles. The amplified products were fractionated on a $2 \%$ agarose gel containing $0.5 \mu \mathrm{g} / \mathrm{ml}$ ethidium bromide, gels were photographed with Polaroid film (Polaroid type 667), and photographs were quantitatively scanned using the $\mathrm{NIH}$ image software. The efficiency of cDNA synthesis from each sample was estimated by PCR with GAPDH-specific primers.

\section{Flow cytometric analysis of mitochondrial membrane potential}

Mitochondrial membrane potential was measured with the tetramethylrhodamine, ethyl ester, per chlorate (TMRE, Molecular Probe Inc., Eugene, OR, USA) using flow cytometry as described previously. ${ }^{41}$ Treated cells were collected with trypsinization, washed twice with PBS, and stained with $150 \mathrm{nM}$ TMRE in PBS in the dark at $37^{\circ} \mathrm{C}$ for $30 \mathrm{~min}$. Samples were washed and resuspended with PBS containing $15 \mathrm{nM}$ TMRE and then analyzed with the FACScan using CellQuest software.

\section{Caspase- 3 activity assay}

Caspase- 3 activity assay was performed using the Cleavalite ${ }^{\mathrm{TM}}$ caspase- 3 activity assay kit (Chemicon International, Temecula, CA, USA) according to the manufacturer's instructions. Treated cells were trypsinized, and washed in PBS. The cell pellets were incubated in Cell Lysis Buffer of the kit on ice for $10 \mathrm{~min}$ and centrifuged at $10000 \times g$ for $5 \mathrm{~min}$. Cell lysate was incubated at $37^{\circ} \mathrm{C}$ for $1-2 \mathrm{~h}$ with a bioluminescent substrate for caspase-3, which has a Renilla luciferase containing the caspase-3 cleavage site, DEVD. Upon cleavage, it exhibits decreased bioluminescence.

\section{Immunofluorescence staining}

Tumor cells were cultured on the chamber slide dish (Nalge Nunc International, Naperville, IL, USA). After treatment, cells were fixed in $4 \%$ paraformaldehyde, blocked with $3 \%$ normal goat serum, stained with anticathepsin B antibody (Calbiochem, La Jolla, CA, USA) and anti-Lamp-1 antibody (BD Transduction Laboratories, Palo Alto, CA, USA), and visualized with a goat anti-mouse or goat anti-rabbit IgG conjugated with Alexa fluorochromes (Molecular Probe, Eugene, OR, USA) and examined under a fluorescence microscope as described previously. ${ }^{42}$

\section{Statistical analysis}

The data were expressed as means \pm S.D. Statistical analysis was performed by using Student's $t$-test (two-tailed). The criterion for statistical significance was taken as $P<0.05$.

\section{Acknowledgements}

We thank Dr. T Yoshimori and Dr. N Mizushima for GFP-LC3 expression vector and the Schering-Plough Research Institute for TMZ. We also thank Dr. A Yamamoto and Dr. N Mizushima for helpful suggestions. This study was supported in part by the USPHS Grant 1R01 CA88936 (SK) awarded by the National Cancer Institute, in part by a start-up fund from The University of Texas MD Anderson Cancer Center, and in part by a generous donation from the Anthony D Bullock III Foundation. 


\section{References}

1. Mahaley MS, Mettlin C, Matarajan N, Laws ER and Peace BB (1989) Nationa survery of patterns of care for brain-tumor patients. J. Neurosurg. 71: 826-836

2. Avgeropoulos NG. and Batchelor TT (1994) New treatment strategies for malignant gliomas. Oncologist 4: 209-224

3. Bower M, Newlands ES, Bleehen NM, Brada M, Begent RJ, Calvert $H$, Colquhoun I, Lewis P and Brampton MH (1997) Multicentre CRC phase II trial of temozolomide in recurrent or progressive high-grade glioma. Cancer Chemother. Pharmacol. 40: 484-488

4. Yung WK, Prados MD, Yaya-Tur R, Rosenfeld SS, Brada M, Friedman HS, Albright R, Olson J, Chang SM, O'Neill AM, Friedman AH, Bruner J, Yue N, Dugan M, Zaknoen S and Levin VA (1999) Multicenter phase II trial of temozolomide in patients with anaplastic astrocytoma or anaplastic ligoastrocytoma at first relapse. Temodal Brain Tumor Group. J. Clin. Oncol. 17: $2762-2771$

5. Stevens MF, Hickman JA, Stone R, Gibson NW, Baig GU, Lunt E and Newton CG (1984) Antitumor imidazotetrazines. 1. Synthesis and chemistry of 8 carbamoyl-3-(2-chloroethyl)imidazo-1,2,3,5-tetrazin-4(3H)-one , a novel broadspectrum antitumor agent. J. Med. Chem. 27: 196-201

6. Newlands ES, Stevens MF, Wedge SR, Wheelhouse RT and Brock C (1997) Temozolomide: a review of its discovery, chemical properties, pre-clinical development and clinical trials. Cancer Treat. Rev. 23: 35-61

7. Agarwala SS and Kirkwood JM (2000) Temozolomide, a novel alkylating agent with activity in the central nervous system, may improve the treatment of advanced metastatic melanoma. Oncologist 5: 144-151

8. Friedman HS, Kerby T and Calvert $\mathrm{H}$ (2000) Temozolomide and treatment of malignant glioma. Clin. Cancer Res. 6: 2585-2597

9. Denny BJ, Wheelhouse RT, Stevens MF, Tsang LL and Slack JA (1994) NMR and molecular modeling investigation of the mechanism of activation of the antitumor drug temozolomide and its interaction with DNA. Biochemistry 33 : 9045-9051

10. D'Atri S, Piccioni D, Castellano A, Tuorto V, Franchi A, Lu K, Christiansen N, Frankel S, Rustum YM and Papa G (1995) Chemosensitivity to triazene compounds and $0^{6}$-alkylguanine-DNA alkyltransferase levels: studies with blasts of leukaemic patients. Ann. Oncol. 6: 389-393

11. D'Atri S, Tentori L, Lacal PM, Graziani G, Pagani E, Benincasa E, Zambruno G, Bonmassar E and Jiricny J (1998) Involvement of the mismatch repair system in temozolomide-induced apoptosis. Mol. Pharmacol. 54: 334-341

12. Hirose $Y$, Berger MS and Pieper RO (2001) p53 effects both the duration of G2/ $\mathrm{M}$ arrest and the fate of temozolomide-treated human glioblastoma cells. Cancer Res. 61: 1957-1963

13. Kondo S, Barna BP, Morimura T, Takeuchi J, Yuan J, Akbasak A and Barnett GH (1995) Interleukin-1 $\beta$-converting enzyme mediates cisplatin-induced apoptosis in malignant glioma cells. Cancer Res. 55: 6166-6171

14. Bursch W, Ellinger A, Kienzl H, Torok L, Pandey S, Sikorska M, Walker R and Hermann RS (1996) Active cell death induced by the anti-estrogens tamoxifen and ICl 164384 in human mammary carcinoma cells (MCF-7) in culture: the role of autophagy. Carcinogenesis 17: 1595-1607

15. Paglin S, Hollister T, Delohery T, Hackett N, McMahill M, Sphicas E, Domingo D and Yahalom J (2001) A novel response of cancer cells to radiation involves autophagy and formation of acidic vesicles. Cancer Res. 61: 439-444

16. Yao KC, Komata T, Kondo Y, Kanzawa T, Kondo S and Germano IM (2003) Molecular response of human glioblastoma multiforme cells to ionizing radiation: cell cycle arrest, modulation of the expression of cyclin-dependent kinase inhibitors, and autophagy. J. Neurosurg. 98: 378-384

17. Kanzawa $T$, Kondo $Y$, Ito $H$, Kondo $S$ and Germano I (2003) Induction of autophagic cell death in malignant glioma cells by arsenic trioxide. Cancer Res. 63: 2103-2108

18. Kabeya Y, Mizushima N, Ueno T, Yamamoto A, Kirisako T, Noda T, Kominami E, Ohsumi Y and Yoshimori T (2000) LC3, a mammalian homologue of yeast Apg8p, is localized in autophagosome membranes after processing. EMBO J. 19: $5720-5728$

19. Mizushima N, Yamamoto A, Hatano M, Kobayashi $Y$, Kabeya $Y$, Suzuki $K$, Tokuhisa T, Ohsumi Y and Yoshimori T (2001) Dissection of autophagosome formation using Apg5-deficient mouse embryonic stem cells. J. Cell Biol. 152 $657-668$

20. Kim J and Klionsky DJ (2000) Autophagy, cytoplasm-to-vacuole targeting pathway, and pexophagy in yeast and mammalian cells. Annu. Rev. Biochem. 69: 303-342
21. Yamamoto A, Tagawa $Y$, Yoshimori T, Moriyama $Y$, Masaki $R$ and Tashiro $Y$ (1998) Bafilomycin A1 prevents maturation of autophagic vacuoles by inhibiting fusion between autophagosomes and lysosomes in rat hepatoma cell line, $\mathrm{H}-4$ II-E cells. Cell Struct. Funct. 23: 33-42

22. Manabe T, Yoshimori T, Henomatsu N and Tashiro $Y$ (1993) Inhibitors of vacuolar-type $\mathrm{H}(+)$-ATPase suppresses proliferation of cultured cells. J. Cell. Physiol. 157: 445-452

23. Munafo DB and Colombo Ml (2001) A novel assay to study autophagy: regulation of autophagosome vacuole size by amino acid deprivation. J. Cell Sci. 114: 3619-3629

24. Nara A, Mizushima N, Yamamoto A, Kabeya $Y$, Ohsumi $Y$ and Yoshimori $T$ (2002) SKD1 AAA ATPase-dependent endosomal transport is involved in autolysosome formation. Cell Struct. Funct. 27: 29-37

25. Boya $\mathrm{P}$, Gonzalez-Polo RA, Poncet D, Andreau K, Vieira $\mathrm{HL}$, Roumier $\mathrm{T}$, Perfettini $\mathrm{JL}$ and Kroemer $\mathrm{G}$ (2003) Mitochondrial membrane permeabilization is a critical step of lysosome-initiated apoptosis induced by hydroxychloroquine. Oncogene 22: 3927-3936

26. Seglen PO and Bohley P (1992) Autophagy and other vacuolar protein degradation mechanisms. Experientia 48: 158-172

27. Blommaart EF, Krause U, Schellens JP, Vreeling-Sindelarova $H$ and Meijer AJ (1997) The phosphatidylinositol 3-kinase inhibitors wortmannin and LY294002 inhibit autophagy in isolated rat hepatocytes. Eur. J. Biochem. 243: 240-246

28. Vanhaesebroeck B, Leevers SJ, Panayotou G and Waterfield MD (1997) Phosphoinositide 3-kinases: a conserved family of signal transducers. Trends Biochem. Sci. 22: 267-272

29. Toker A and Cantley LC (1997) Signalling through the lipid products of phosphoinositide-3-OH kinase. Nature 387: 673-676

30. De Camilli P, Emr SD, McPherson PS and Novick P (1996) Phosphoinositides as regulators in membrane traffic. Science 271: 1533-1539

31. Petiot A, Ogier-Denis E, Blommaart EF, Meijer AJ and Codogno P (2000) Distinct classes of phosphatidylinositol $3^{\prime}$-kinases are involved in signaling pathways that control macroautophagy in HT-29 cells. J. Biol. Chem. 275: 992-998

32. Klionsky DJ and Ohsumi Y (1999) Vacuolar import of proteins and organelles from the cytoplasm. Annu. Rev. Cell Dev. Biol. 15: 1-32

33. Liang XH, Jackson S, Seaman M, Brown K, Kempkes B, Hibshoosh $\mathrm{H}$ and Levine B (1999) Induction of autophagy and inhibition of tumorigenesis by beclin 1. Nature 402: 672-676

34. Arico S, Petiot A, Bauvy C, Dubbelhuis PF, Meijer AJ, Codogno P and OgierDenis E (2001) The tumor suppressor PTEN positively regulates macroautophagy by inhibiting the phosphatidylinositol 3-kinase/protein kinase B pathway. J. Biol. Chem. 276: 35243-35246

35. Ogier-Denis E and Codogno P (2003) Autophagy a barrier or an adaptive response to cancer. Biochim. Biophys. Acta 1603: 113-128

36. Altan N, Chen Y, Schindler M and Simon SM (1998) Defective acidification in human breast tumor cells and implications for chemotherapy. J. Exp. Med. 187: 1583-1598

37. Bursch W, Ellinger A, Gerner C, Frohwein U and Schulte-Hermann R (2000) Programmed cell death (PCD). Apoptosis, autophagic PCD, or others? Ann. NY Acad. Sci. 926: 1-12

38. Bursch W, Hochegger K, Torok L, Marian B, Ellinger A and Hermann RS (2000) Autophagic and apoptotic types of programmed cell death exhibit different fates of cytoskeletal filaments. J. Cell Sci. 113 (Part 7): 1189-1198

39. Komata T, Kondo Y, Koga S, Ko SC, Chung LW and Kondo S (2000) Combination therapy of malignant glioma cells with 2-5A-antisense telomerase RNA and recombinant adenovirus p53. Gene Therapy 7: 2071-2079

40. Komata T, Kondo Y, Kanzawa T, Hirohata S, Koga S, Sumiyoshi H, Srinivasula SM, Barna BP, Germano IM, Takakura M, Inoue M, Alnemri ES, Shay JW, Kyo $S$ and Kondo S (2001) Treatment of malignant glioma cells with the transfer of constitutively active caspase- 6 using the human telomerase catalytic subunit (human telomerase reverse transcriptase) gene promoter. Cancer Res. 61: 5796-5802

41. Bruick RK (2000) Expression of the gene encoding the proapoptotic Nip3 protein is induced by hypoxia. Proc. Natl. Acad. Sci. USA 97: 9082-9087

42. Koga $S$, Hirohata $S$, Kondo $Y$, Komata $T$, Takakura M, Inoue $M$, Kyo $S$ and Kondo S (2000A) Novel telomerase-specific gene therapy: gene transfer of caspase-8 utilizing the human telomerase catalytic subunit gene promoter. Hum. Gene Ther. 11: 1397-1406 